Karadeniz Uluslararası Bilimsel Dergi

Volume: 52, Winter-2021, p. (149-165)

ISSN: 1308-6200 DOI Number: https://doi.org/10.17498/kdeniz.998437

Research Article

Received: Sep 21, 2021 | Accepted: Nov 12, 2021

This article has been checked for plagiarism.

\title{
TOPLUMSAL VE KÜLTÜREL BİR İÇECEK: "TÜRK KAHVESİ”
}

\section{A SOCIETAL AND CULTURAL BEVERAGE: "TURKISH COFFEE" \\ СОЦИАЛЬНО-КУЛЬТУРНЫЙ НАПИТОК: “КОФЕ ПО ТУРЕЦКИ”}

Jale KARHAN*

ÖZ

Anavatanı Afrika olan kahve Avrupa'ya Türkler tarafindan tanıtılmıştır. Türk kültürünün en önemli içeceği olarak tarihi, siyasi, sosyal ve kültürel bir geçmişe sahip olan "Türk kahve"si hazırlanışı, araç ve gereçleri, sunumu ve ritüelleriyle birlikte soyut ve somut bütün kültürel unsurlarıyla beraber atasözlerine, deyimlere, halk bilmecelerine, türkülere, resimlere ve şiirlere konu olmuştur. Türk kahvesi ülkemizde sosyal bir içecek olarak önemli bir toplumsallaşma ve kültürel iletişim araçlarındandır. Özel günler, dini bayramlar, komşu ziyaretleri, dost ve arkadaş çevrelerinde bir bardak su ile ikram edilen Türk kahvesi beraberinde birçok anlamı iletir.

Türk kahvesi ülkemizde farklı etnik, dini, sosyal ve kültürel gruplar arasında üzerinde mutabakata varılmış bir gelenek ve kültür meydana getirmiştir. Türk kahvesi bir kültürel miras olarak sosyolojik açıdan ele alınması gereken önemli bir konudur. $\mathrm{Bu}$ nedenle çalışmada Türk kahvesi kültür ve geleneğinin geçmişten bugüne kadar geçirmiş olduğu toplumsal, tarihsel ve kültürel değişimini anlamak ve sorgulamak adına "tarihsel ve karşılaştırmalı yöntem" kullanılarak sosyolojik bir bakış açısıyla konu ele alınmıştır. Bu bağlamda Türk kahvesi kültür ve geleneği tarihsel, kültürel ve toplumsal bağlamı içinde multidisipliner, çok boyutlu ve eklektik bir şekilde ele alınmış; ayrıca gelecekte bu konu hakkında yapılacak olan çalışmalara da katkı sağlaması umulmuştur. Çalışmanın sonucunda ise sosyolojik, sanatsal, siyasal, ekonomik, tarihi ve kültürel bir değere sahip ve belli bir zamana, coğrafyaya ve tarihe bağlı olarak yakın bir geçmiş zamanda "icat edilmiş" olmayan 500 yıllık bir kültür ve geleneğe sahip olan Türk kahvesi kültürü ve geleneğinin kolay kolay ortadan kalkmayacağı görülmüştür.

Anahtar Kelimeler: Afrika, Türk, Avrupa, Türk kahvesi, kültürel miras.

* ORCID: 0000-0001-9120-4962 Dr. Öğr. Üyesi Artvin Çoruh Üniversitesi Fen-Edebiyat Fakültesi Sosyoloji Bölümü, jalekarhan@artvin.edu.tr 


\section{Toplumsal ve Kültürel Bir İçecek: “Türk Kahvesi”}

\section{ABSTRACT}

Coffee, whose homeland is Africa, was introduced to Europe by Turks. The preparation of "Turkish coffee", which has a historical, political, social, and cultural background as the most important drink of Turkish culture, has been the subject of proverbs, idioms, folk riddles, folk songs, paintings and poems along with all its abstract and concrete cultural elements and its tools, equipment, presentation and rituals. Turkish coffee is an important means of socialization and cultural communication as a social beverage in our country. Turkish coffee served with a glass of water in circles of friends on special occasions, religious holidays, neighboring visits convey many meanings.

Turkish coffee has created a tradition and culture in our country, which different ethnic, religious, social, and cultural groups have agreed upon. As a cultural heritage, Turkish coffee is an important issue to address sociologically. Therefore, to understand and question the social, historical, and cultural change of Turkish coffee culture and tradition from the past to the present, the subject was discussed from a sociological point of view using the "historical and comparative method". In this context, the culture and tradition of Turkish coffee have been dealt with in a multidisciplinary, multidimensional and eclectic way in a historical, cultural and social context; it is also hoped that it will contribute to further studies on this issue. As a result of the study, it was seen that the culture and tradition of Turkish coffee, which has a sociological, artistic, political, economic, historical, and cultural value and has a 500-year-old culture and tradition that has not been "invented" in the recent past, depending on a certain time, geography and history, will not disappear easily.

Keywords: Africa, Turkish, Europe, Turkish coffee, cultural heritage

\section{АННОТАЦИЯ}

Кофе, родиной которого является Африка, завезли в Европу турки. Приготовление “кофе по-турецки”, имеющее историческую, политическую, социальную и культурную основу, как самого важного напитка турецкой культуры, был предметом пословиц, идиом, народных загадок, народных песен, картин и стихов со всеми его абстрактными и конкретными культурными элементами, наряду с его кухонными инструментами и оборудованием, рисунками и ритуалами. Кофе по турецки создал традицию и культуру, которое было принято различными этническими, религиозными, социальными и культурными группами в нашей стране. Кофе по турецки, как культурное наследие - важная проблема, которую необходимо решать с социологической точки зрения. По этой причине в данном исследовании тема обсуждается с социологической точки зрения с использованием "исторического и сравнительного метода", с целью восприятия социальных, исторических и культурных изменения турецкой кофейной культуры и традиций от прошлого к настоящему. В контексте междисциплинарной, высококультурной и эклектичной формы и традиций изучена тема турецкой кофейной культуры.Также есть надежда, что это внесёт вклад в будущие исследования по этой теме. В результате исследования было установлено, что культура и традиции -кофе по турецки, имеющие социологическую, художественную, политическую, экономическую, историческую и культурную ценность, а также культуру и традицию 500-летней давности, которые не были “изобретены” в недавнем прошлом, в зависимости от определенного времени, географии и истории, легко не исчезнет.

Ключевые слова: Африка, Турция, Европа, кофе по-турецки, культурное наследие. 


\section{Giriş}

"Gönül ne kahve ister, ne kahvehane; gönül sohbet ister, kahve bahane.” Atasözü

Gündelik yaşamımızda yer alan kahve içme eylemi hakkında Anthony Giddens'a göre (2012) sosyolojik bir bakış açısıyla söylenebilecek birçok şey vardır. İlkin, kahve sadece bir içecek değildir; zira kahveyi içmenin törensel bir boyutu vardır. Yine bir yudum kahveyi içen birisi, tüm dünyaya yayılmış olan karışık bir sosyal ve iktisadi ilişkilerin içerisinde bulunur; ayrıca kahve bizleri geçmişte yaşanılmış olan sosyal, kültürel, tarihi, siyasi ve ekonomik bir dizi hadiselere götürür (s. 38-40).

Bugün dünyada kabul görmüş ve uzun bir tarihi, siyasi, sosyal ve kültürel bir geçmişi olan "Türk kahvesi" hazırlanışı, araç ve gereçleri, sunumu ve ritüelleri ile birlikte bir kültür ve medeniyet oluşturduğundan sosyolojik ilgiyi fazlasıyla hak etmektedir; çünkü geçmişten günümüze kadar Türk kahvesi özel günler, misafir ağırlamalar, arkadaş ve dost çevrelerinde bir bardak su ile ikram edilerek soyut ve somut kültürel unsurları ile beraber Türk kültürünün en önemli içeceği olarak atasözlerine, deyimlere, halk bilmecelerine, türkülere, resimlere ve şiirlere konu olmuştur. Türk kahvesi üzerine Salâh Birsel (1983), Ralph S. Hattox (1985/1996), Taha Toros (1998), Nâmık Açıkgöz (1999), Emine Gürsoy Naskali (2014), Ersu Pekin (2015), Kemalettin Kuzucu ve M. Sabri Koz (2015), Beşir Ayvazoğlu (2019) ve Elias Petropoulos (1979/2019) tarafindan yapılmış olan kıymetli çalışmalar vardir.

Bu çalışmada Türk kahvesi kültür ve geleneğinin geçmişten bugüne kadar geçirmiş olduğu toplumsal, tarihsel ve kültürel değişimini anlamak ve sorgulamak adına tarih disiplininden faydalanarak "tarihsel ve karşılaştırmalı bir yöntem" (Neuman, 2010, s. 602) kullanılmıştır. Bu kapsamda çalışmada Türk kahvesi kültürü ve geleneği tarihsel, kültürel ve toplumsal bağlamı içinde multidisipliner, çok boyutlu ve eklektik bir şekilde sosyolojik bir bakış açısıyla ele alınmıştır; ayrıca bu konu hakkında bundan sonra yapılacak olan çalışmalara da katkı sağlaması amaçlanmıştır.

\section{Kahvenin Tarihi}

Burçak Evren (1996) kahvenin Arapça bir kelime olduğunu ve ilk zamanlarda şiirde şarap manasında kullanıldığını belirtmiştir (s. 16). C. Van Arendok'a göre (1967) “'k]ahve içmek âdeti Yemen'e, muhtemelen, sûfî çevrelerden geçtiğine ve sûfîlerin nazım lisanında, şaraba husûsî bir mâna verildiğine göre, nazımdaki şarāb kelimesinin yeni içkiye itlak olunduğu farzedilebilir" (s. 95).

\footnotetext{
1 "Sosyolojinin on dokuzuncu yüzyıldaki kurucuları, tarihsel karşılaştırmalı (TK) araştırma yürütmüş, sosyoloji, tarih, siyaset bilimi ve ekonomiyi harmanlamıştır" (Neuman, 2010, s. 603).
} 


\section{Toplumsal ve Kültürel Bir İçecek: “Türk Kahvesi”}

Toros'a göre (1998) kahvenin anavatanı genellikle Yemen olarak bilinse de kahve ilk olarak Yemen'e Habeşistan'dan gelmiş ve orada üretilmiştir (s. 7, 8). Ekrem Işın'a göre (2006) geçmişte Habeşistan'da yerli ahali kahvenin tanelerini un haline getirerek ekmek yapmışlardır. Kahvenin mitolojik serüveni ise bir yiyecekten içeceğe dönüştüğü anda başlamıştır. Peki, bu dönüşüm nasıl meydana gelmiştir? Kahve içmeyi ilk olarak kim keşfetmiştir? (s. 12). Kahvenin keşfiyle alakalı çok çeşitli rivayetler bulunmaktadır.

Bir rivayete göre, Hz. Süleyman yolculuğu esnasında bir kasabaya uğramış ve kasaba halkının meçhul bir hastalığın pençesine düştügünü görmüştür. Cebrail'in emri ile Yemen'den gelen kahve çekirdeklerini kavurarak bir içecek hazırlamış ve hastalara vermiş; böylece içeceği içen hastalar iyileşmiş ve hastalıktan kurtulmuşlar. Rivayetin sonunda kahvenin daha sonra tamamen unutulduğu ve 16. (Hicri 10.) yüzyılın başlarında yeniden ortaya çıktığı belirtilmiştir (Hattox, 1985/1996, s. 10). Kahvenin keşfiyle alakalı diğer bir rivayet, Etiyopyalı Kaldi isimli bir keçi çobanının hikâyesidir. Rivayete göre, çobanın sürüsü gece gündüz sürekli hareket eder ve siçrayıp oynarlar. Çoban yerel bir tekkedeki bazı dervişlere durumu anlatır. Dervişler araştırmaya karar verirler ve sürüyü takip ederler. Keçilerin bölgede yaygın olan yabani bir çalı üzerinde yetişen minik kırmızı yemişlerle beslendiklerini fark ederler. Dervişler meyveleri tattıktan sonra enerji hissederler. Sonrasında bu meyvelerden içecek yaparlar; böylece kahve keşfedilir (Morris, 2020, s. 45; Stella, 1997, s. 17). Bir diğer mühim rivayet ise Cenk R. Girginol'a göre (2018) Tarihçi Ahmet Efendi'ye göre kahvenin keşfedilmesi Şazeli dergâhından bir derviş ile başlamıştır. Gerçek ismi Nureddin Ali bin Abdullah (lakabı Ebu'l-Hasan Şazeli) olan bu zat Habeşistan'da bir dergâhın erbabıdır. 700'lü yılların başında tekkesinden kovularak dağlara sürgün edildiğinde görmüş olduğu kahve tanelerinden önce ekmek yaparak hayatta kalmıştır. Bu kullanım yayılmış ve kahvenin başlangıcını oluşturmuştur; böylece kahvenin dünyadaki yolculuğu başlamıştır (s. 14).

\section{Kahvenin Osmanlı'ya Girişi ve Kahvehaneler}

Anavatanı Afrika olan kahve Osmanlı'ya ilk girdiği andan itibaren sosyal, kültürel, gündelik, iktisadi, siyasi ve dini yaşamı köklü bir şekilde etkilemiştir. Cemal Kafadar'a göre (2014) kahvehanelerin değil kahvenin Osmanlı devletindeki ilk bahsi Barbaros Hayrettin Paşa'nın bağış belgesinde görülür. Barbaros'un 1539 yılında kaydettirdiği aile vakfina ait mülklerinden biri olarak bağışladığı evinde birde kahve odası bulunmaktaydı (s. 247). Kâtip Çelebi ise kahvenin, gemilerle 950 (1543) tarihinde İstanbul'a geldiğini kaydetmiştir (2018, s. 65). Kuzucu'ya göre (2015) kahve İstanbul'a geldiğinde ilk başta tarikatların ilgisini çekmiş; böylece Kalenderî, Halvetî ve Bektaşî tekkelerinin vazgeçilmez bir içeceği olmuştur. Halvetî tarikatı mensubu olan Kanunî Sultan Süleyman'ın sarayında kahvecibaşılık kurumu kurulmuş. Afrika kökenli kahvenin çabucak saray mensuplarından toplumun en alt kesimlerine kadar tüm çevrelerde tutku haline gelmesi kahvehanelerin kurulmasına neden olmuştur (s. 37). 
Hattox'un (1985/1996) "şarapsız meyhaneler” (s. 64) olarak nitelendirdiği kahvehanenin İstanbul'da ilk açıldığı tarihle alakalı kaynaklarda farklı görüşler bulunmaktadır. Tarihçi Gelibolulu Mustafa Âli İstanbul'da açılan ilk kahvehanenin tarihini 1552/1553 olarak belirtmiştir (Ayvazoğlu, 2019, s. 29; Kuzucu, 2015, s. 133; Sökmen, 2019, s. 29, 30). Tarihçi Peçevi İbrahim Efendi ise 962 (1554) tarihine gelene kadar İstanbul'da kahve ve kahvehanenin olmadığını ve bu yılın başlarında Halep'ten Hakem ve Şam'dan Şems isimli iki kişinin gelerek Tahtakale'de açtıkları dükkânda kahve sattıklarını kaydetmiştir (1981, s. 258).

Kahve tüketimi ve kahvehaneler Osmanlı imparatorluğunda ulema ve merkez yönetimi tarafindan çok sert tepkiler ve yasaklarla karşılaşmıştır. Bilhassa, kahvehanelerde merkezi iktidarın aleyhine yapılan ve bazı dönemlerde devlete yönelik isyanların olmasına neden olan "devlet sohbetleri" olarak adlandırılan kahvehane sohbetleri siyasi otorite tarafından tehdit olarak algilandığından kahvehaneler "fitne ve fesat yuvaları" olarak görülmüsstür. $\mathrm{Bu}$ nedenle kahvehaneler siyasi otorite tarafindan kimi zaman toptan kapatılmaya maruz kalmış kimi zaman kapatılmayarak farklı stratejilerle denetim ve kontrol altına alınmıştır; ancak kahvenin önemli bir gelir kaynağı olması -yani ticari boyutusebebiyle bu yasaklamalar çoğu zaman geçici olmuştur veya ihlal edilmiştir.

Ayşe Saraçgil'e göre (1999) ulemanın kahveye yönelik olumsuz tepkisinin iki nedeni vardı. Birincisi, kahve çekirdeklerinin kavrulma aşamasında kömürleşmesidir. ${ }^{2}$ İkincisi, kahvenin halk arasındaki tüketimiyle ilgilidir; çünkü ulemaya göre kahve içerken davetliler arasında fincanın elden ele dolaştırılması keyif verici ve yasak içkilerin tüketimini andırmaktadır (s. 28). ${ }^{3}$ Marianna Yerasimos'a göre (2019) ulema arasında kahve üzerine tartışmalar 16. ve kısmen 17. yüzyıla kadar sürmüştü. Evliyâ Çelebi ise kahve içmediği halde kahve içenlere karşı değildir. Kahvehanelerin -ayrıca meyhane ve bozahanelerin- kapatılmasını da tasvip etmez ve bu hususta zalimliğe varan önlemlerinden dolayı IV. Murad'1 kinar (s. 205, 206).

Osmanlı'da mahalle, yeniçeri, tulumbacı, esnaf, imaret, esrarkeş, tiryaki, seyyar, âşı, meddah ve semai kahvehaneleri başlıca kahvehane çeşitleridir (Evren, 1996, s. 47-106; Sökmen, 2019, s. 31-46). Yerasimos'a göre (2019) Evliyâ Çelebi, "mekteb-i irfân misilli" -yani ilim ve irfan okulu gibi- dediği kahvehanelerin farklı kökenden ve toplumun değişik kesimlerinden gelen insanlarla dolu olan mekânlar olduğunu nakleder. Kahvehaneler, bilgili kişilerin dışında her çeşit insanın bir araya gelerek vakit geçirdiği ve sohbet ettiği mekânlardır. Evliyâ Çelebi'nin belirttiğine göre bazı kahvehanelerde gazelhanlar, kıssahanlar, meddah, çalgıcı ve rakkaslar sanatlarını gerçekleştirirlerdi. Şöyle ki kahvehaneler yalnızca vakit geçirilen ve sohbet edilen yerler değil; bununla birlikte önemli eğlence merkezleriydi (s. 206-208).

\footnotetext{
2 Saraçgil'e göre (1999) Hanefî mezhebinde cansız bir madde İslami geleneğin yeme içme alışkanlıkları arasında yer alamaz. Kahveye gelince kavrulmuş çekirdekler kömürleşme aşamasına gelmekte ve bu durum da kahve kullanımını haram kılmaktadır (s. 28).

${ }^{3}$ Kahve yasakları konusunda daha ayrıntılı bilgi için (bkz. Arendonk, 1967, s. 98, 99; Çelebi, 2018, s. 65, 66; Peçevi, 1981, s. 258, 259).
} 


\section{Toplumsal ve Kültürel Bir İçecek: “Türk Kahvesi”}

Alan Mikhail (2014) Jürgen Habermas'ın kamusal mekânla alakalı savlarının Osmanlı devletindeki kahvehaneleri araştıranlara çekici gelse de Osmanlı kahvehanelerini ve bu kahvehanelerin Osmanlı şehirlerindeki rollerini düşünürken fayda sağlamadığını bilâkis engel oluşturduğunu belirtir. Mikhail, Osmanlı mekânlarını -ki kahvehaneler bunun ayrılmaz bir parçasıkavramsallaştırırken meseleye çizgiler ve sınırlar açısından değil katmanlar ve çokluk açısından yaklaşılması gerektiğini; dolayısıyla Osmanlı kahvehanelerini Habermas'ın ikilikler üzerine kurduğu katı dünyası yerine Michel Foucault'nun "heterotopya" kavramiyla ele almayı önerir (s. 178-181). Foucault (2005) heterotopyanın birçok mekânı ve mevkiyi, kendi içlerinde uzlaşmayan birçok mekânı tek bir gerçek mekânda yan yana yerleştirme gücü bulunduğunu belirtir (s. 298). İlyaz Bingül'e göre (2013) Osmanlı kahvehaneleri fiskiyeli havuzu olan avlusu ve hat yazılarıyla cami ve tekkeyle; meddah, hokkabaz ve karagöz gibi oyunlarıyla şenlik ve şölen alanıyla; köçeği, çengicisi ve çalgıcılarıyla meyhaneyle; afyon, kumar ve fuhuşuyla batakhaneyle; eleştiri, dedikodu ve "devlet sohbeti"yle gazete ve siyasi partilerle; afyon, berş ve hacamatıyla eczahaneyle; taş ustaları, sucuları vb. hüner sahipleriyle iş ve işçi bulma kurumuyla; Battalname, Hamzaname vb. türden kitaplarıyla kütüphaneyle ilişki içerisinde olan heterotopik mekânlardır (s. 134).

\section{Kahvenin Osmanlı Tarafindan Avrupa'ya Yayılması}

Kahve, Avrupa'ya ilk olarak 17. yüzyılın başlarında Venedikli tüccarlar tarafından getirilmiştir (Moon, 1998, s. 9). Ayrıca kahvenin yaygınlaşması ile birlikte Avrupa'da kahvehanelerde açılmıştır. Dönemin önde gelen entelektüelleri, düşünürleri ve edebiyatçıları bu kahvehanelere giderek edebi, sosyal, kültürel, siyasi ve entelektüel tartışmalar yapmışlardır. Richard Sennett (2013) kahvehanelerin Paris ve Londra gibi şehirlerde başta gelen enformasyon merkezleri olduğunu ve gazetelerin kahvehanelerde okunduğunu belirtir (s. 116, 117).

Kuzucu'ya göre (2015) kahvenin Avrupa'ya tanitılması Türkler tarafindan olmuştur. Avrupa toplumu, kahveyi, ilkin Doğu'ya bilhassa İstanbul ile diğer Osmanlı şehirlerine giden diplomatlar ile gezginlerin yazılarıyla tanımışlardır. Gezginler $^{4}$ Türklerin kahveye olan düşkünlügünü, kullanılan malzemeleri, kahvenin hazırlanmasını, ikram ve içim tarzını uzun uzun anlatmışlardır; ayrıca gezginlerin dışında elçilik gibi resmi görevlerle gelenler de raporlarında Türk kahvesinden söz etmişlerdir (s. 101).

Claude Fischler'e göre (1988) gida kimlik duygumuzun merkezinde yer alır ve herhangi bir grubun yemek yeme tarzı grubun farklılığını, hiyerarşisini ve örgütlenmesini; ayrıca grubun hem teklik hem de farklı şekilde yiyen gruplardan ötekiliğini ortaya koymasına yardım eder (s. 275). Priscilla Parkhurst Ferguson'a göre (2011) sosyal, siyasi, dini, kültürel ve etnik kimliğe dair konularla insanların ilk karşılaşmaları damak zevkleri vasıtasıyla olmaktadır. İnsanların yedikleri

\footnotetext{
${ }^{4}$ Fransız seyyah Jean Thévenot seyahatnamesinde Türklerin içtiği içeceklerden bahsederken kahve ve kahvehanelerden söz etmiştir. Daha ayrıntılı bilgi için ayrıca (bkz. Thévenot, 2014, s. 69, 70).
} 
yemekler ve içtikleri içecekler yetiştikleri yer, ait oldukları ve içerisinde yaşadıkları sosyal mekânlarla ilişkilidir. Diğer bir ifade ile insanların yedikleri yemekler ve içtikleri içecekler kim olduklarına ilişkin birçok bilgiyi iletir (aktaran Ichijo ve Ranta, 2016/2018, s. 39).

İçecek sadece fizyolojik bir olgu değildir; bunun yanı sıra sosyal, kültürel, siyasi, etnik ve dinsel sebeplerden dolayı bir toplumsal grubun kimlik meselesi haline gelir. İçecekler toplumsal kimliğin oluşumunda önemli olduğundan her kültürün ve dinin bu konuda belirli kuralları vardır. Örneğin kahve Osmanlı da tıpk1 Avrupa'da olduğu gibi ilk başlarda haram olup olmadığ1 konusunda din adamları arasında tartışmalara neden olmuştur. Her toplumda içecekler konusunda neyin haram neyin helal olduğuna yönelik yapılan bu tartışmalar o toplumun içecek kültürünü şekillendirir. Bu tartışmalar; toplumlar arasında var olan farklılığı ortaya koyarak kolektif ve kültürel kimliğin gerçekleşmesine; toplumsal gruplar arasında "biz" ve "diğerleri”" şeklinde bir sınır çizerek insanların toplumsal, kültürel, siyasi, etnik ve dinsel olarak hangi gruba ait oldukların belirlemeye neden olur.

Elbette insanlar doğumlarından ölümlerine kadar ailenin dışında farklı sosyal gruplara girerek sosyalleştiklerinden bireysel tercihleri zamanla değişebilir ve içinde bulundukları toplumun kültürel ve dini nedenlerle yasaklamış olduğu şeylerini içebilirler; örneğin İslam toplumlarında alkollü içecekler yasak olmasına rağmen içilmektedir. Ancak bir insanın içtiği içecek onun hangi siyasi, etnik, dini, sosyal ve kültürel topluluğun üyesi olduğunun bir göstergesi olduğundan, yasak olan bir içeceğin içilmesi o toplumun kültürel, sosyal ve dini beklentilerine uymadığında ve dayanışmasını, bütünleşmesini, sürekliliğini ve dengesini tehdit ettiğinde, yasak olan içeceği içenin mensubu olduğu topluluk tarafından ayıplanmasına, kınanmasına ve günahkâr sayılmasına; kısacası grubunun dışına itilmesine neden olabilir. İşte Avrupa toplumu da Müslüman ve Türk içeceği olarak gördüğu kahveyi etnik, siyasi, sosyal, kültürel ve dini sebeplerden dolayı ilk başlarda hoş karşılamamıştır. Avrupalılar "etnomerkezci" bir tutumla kahveyi "İslamın şarabı", "Müslüman içkisi", "kâfirlerin içeceği”, "şeytan içkisi”, "Türk içeceği" vb. şekilde adlandırmışlardır; dolayısıyla kahve Avrupa da yayılırken bir takım yasaklamalar ve tepkilerle karşılaşmıştır.

Her toplumda olduğu gibi Avrupa toplumu da mutfak kültürünü muhafaza etmek istemiştir; çünkü mutfak kültürü sosyal, kültürel, etnik ve dini sistemin bir göstergesidir. Avrupalılar kendi toplumlarının toplumsal bütünleşmesini, dayanışmasını ve dengesini korumak amacıyla başlangıçta kahveye tepki koysalar da farklı toplumlar arasında var olan kültürel alışverişler neticesinde toplumsal çatışma ve değişmede kaçınılmazdır; dolayısıyla içecek kültürü de bu toplumsal çatışma ve değişmeden nasibini alır. Işın'a göre (2006) Vatikan'ın kahveye gösterdiği tepki Protestan kilisesi tarafından önemsenmemiş ve kahvenin Avrupa'da yaygın olan içki kullanımına karşı bir seçenek olduğu savunulmuştur. Protestan kültürü, alkolün meydana getireceği zarara karşı kahveyi adeta püriten ahlakın bir havarisi gibi kutsamış; böylece kahve Avrupa'daki burjuva sınıfının koruyucu kanatları altına girerek bir çatışma konusu olmaktan çıkmışır (s. 21). Wolfgang Schivelbusch'a göre (1980/2000) “[b]u noktada, kahve tarihsel olarak 


\section{Toplumsal ve Kültürel Bir İçecek: “Türk Kahvesi”}

önemli bir uyarıcı madde işlevi görür. Kahve bedenin içine işleyerek, rasyonalizm ve Protestan etiğinin ideolojik-düşünsel açıdan yaptığını, kimyasal-farmakolojik olarak gerçekleştirir. (...) Sonuç, yeni talepler doğrultusunda işleyen, rasyonalist ve burjuva-ilerlemeci bir bedendir" (s. 49).

Aslında kahvenin tıpkı tadı ve rengi gibi Avrupa'da acı ve kara bir mazisi vardır. Kahve, geçmişte, Avrupalılar tarafindan bir insanlık suçu olan köle ticaretine ve sömürüsüne bağlı olarak üretilen bir sömürge maddesi olmuştur. Günümüzde ise geçmişin sömürge düzeni ortadan kalmış olmasına rağmen, sömürge anlayışı yeni bir görünüm ile farklı araçlar kullanarak hala devam etmektedir. Antony Wild (2005) bugün kahve dünyası içerisinde Batı yarımkürenin devam eden önemini bölgenin köleliğe dayalı olan geçmiş sömürge plantasyon ekonomilerinden kaynaklandığını belirtir (s. 123). Giddens'a göre (2012) günümüzde içtiğimiz kahve Avrupa ülkeleri tarafından sömürgeleştirilen Güney Amerika ve Afrika gibi ülkelerden getirilmektedir. Küresel kahve ticareti üzerinde sömürge mirasının büyük bir etkisi olmuştur; ayrıca kahve günümüzde insan hakları, küreselleşme, uluslararası ticaret, çevre tahribatı gibi tartışmaların merkezinde olan bir üründür (s. 40).

\section{Toplumsal Bir İçecek Olarak "Türk Kahvesi” Kültürü}

Türk kahvesi kavrulmasından-ögütülmesine, kullanılan araç gereçlerinden, pişirilmesine ve sunumuna kadar ülkemizde farklı etnik, dini, sosyal ve kültürel gruplar tarafindan üzerinde mutabakata varılmış bir gelenek ve kültür oluşturmuştur. Günümüzde özellikle küreselleşmenin de etkisiyle kültürler arasındaki etkileşimin daha fazla artmasıyla dünyanın neresine gidilirse gidilsin Türk kahvesi adı ve kimliği uluslararası alanda kültürel olarak kabul görmüştür. Yalnızca Yunanlılar Türk kahvesine "Yunan kahvesi” demişlerdir. Fakat Yunanlı folklor araştırmacısı Petropoulos (1979/2019) Türklerin Yunanlılara miras bıraktığı şeyler arasında meşhur Türk kahvesinin de yer aldığını ve Yunanca'da kullanılan kafes, kafenes, kafecis, tabis, yedeki, briki, flincani, delves, kavurdistiri, kaymaki, cezves vb. sözcüklerin Türk kökenli olduğunu belirtmiştir (s. 20). Kahve ülkemizde yetiştirilmemektedir. Aslında Türk kahvesi bir kahve pişirme metodudur. Meltem Ahıska ve Zafer Yenal (2006) ülkemizde dünyaca ünlü hazır kahve markalarının ortaya çıkmasıyla beraber eskiden bu yana bildiğimiz "kahve"nin adının "Türk kahvesi" olarak anılmaya başladığını belirtmişlerdir (s. 282).

Alan Beardsworth ve Teresa Keil'e göre (2011) besin ve yemek konusunda yapısalcı bir yaklaşıma sahip olan Roland Barthes için bir besin öğesi bir bilgi öğesidir; dolayısıyla besinler, yemekler ve içecekler bir iletişim sistemindeki göstergeler olarak görülebilir (s. 109, 110). Erhan Akarçay'a göre (2016) "[s]onuç itibariyle Barthes' 1 bir iletişim sistemi olarak gördüğü yiyecekler, içecekler sahip oldukları tekil anlamlardan çok daha fazla anlam, kültürel anlam(lar) içermektedir" (s. 66). Türk kahvesi kültürümüzde o kadar önemli bir yere sahip olmuştur ki "Bir fincan acı kahvenin kırk yıl hatırı vardır", "Kahvenin yüzü kara, ama yüz ağartır" diye atasözlerimizde yerini almış ve sosyal bir içecek olarak en önemli toplumsallaşma ve kültürel iletişim araçlarından birisi olmuştur. Türk kahvesi 
günümüzde hala ülkemizde misafirperverliğin bir göstergesi olarak ikram esnasında hazır kahve çeşitlerine rağmen tahtını kimseye kaptırmamıştır. Serap Savaş Işıkhan'a göre (2014) Türk kahvesi ikramı dostlukların kurulmasında ve pekişmesinde mühim bir yer tutar. Günümüzde her Türk evinde kahve ikramı muazzam bir önem taşır ve kahvenin kabulü ikram edeni şereflendirir. "Kahvesi içilir olmak" ve "bir kahveni içerim" deyişleri bu durumu anlatır. Paylaşılan kahvenin süreklilik arz eden bir manası vardır. Barışı, dostluğu, mutluluğu, sevgi ve saygıyı simgeler. "Bir fincan acı kahvenin kırk yıl hatırı vardır" sözü özlü bir şekilde bunu anlatır (s. 416).

David Swartz'a göre (1997/2011) yeme ve içmede fizyolojik bir ihtiyac1 karşılamak gibi olağan bir işlev âdâb-1 muaşeret kurallarının ve toplumsallaşmanın hâkim olduğu törensel bir ritüel şeklinde biçimselleştirilir (s. 233). Nihal Bursa'ya göre (2015) kendine mahsus pişirilme yöntemiyle Türk kahvesi dünyadaki diğer kahve çeşitlerinden çok farklı özelliklere sahiptir. Türk kahvesi yalnızca bir içecek değildir; belirli bir usul ve adapla beraber var olan kültürel bir oluşumdur. Türk kahvesinin hazırlanması ve içilmesi esnasında kullanılan ve günümüzde artık geleneksel olarak adlandırdığımız usuller, nerdeyse müzelik nesneler haline gelen kahve araç ve gereçlerine bakıldığında, sözünü ettiğimiz eylemlerin törensel bir şekle büründügünü ve beraberinde belirli bir âdâbın oluştuğunu görürüz (s. 239, 240). Türkiye'de birtakım araç ve gereç, usul, ritüel ve kurallarıla törensel ve seremonik bir havada hazırlanan bir Türk kahvesini yudumlamak adeta toplumsal bir etkinliğe dönüşür; ayrıca sosyal ve kültürel olarak birçok göstergelere sahiptir. Komşu ziyareti, misafirlik, altın günü, söz kesme, taziye ziyareti, dini bayramlar vb. özel gün ve zamanlarda ${ }^{5}$ bir bardak su ile ikram edilen Türk kahvesine işlevselci bir yaklaşımla bakıldığında toplumsal dayanışmayı, düzeni, sürekliliği, etkileşimi, birlikteliği ve paylaşımı sağladığı görülür. Türk kahvesi ülkemizde içildiği zamana, mekâna ve bağlama göre birçok anlamı beraberinde iletir. Örneğin taziye evinde acının paylaşımını, misafirlikte konukseverliği ve arkadaş ortamında dostluğu çağrıştırır. Bu mekân ve zamanlarda içilen bir Türk kahvesi küresel kahve zincirlerinde bir "simülasyon" (Baudrillard, 1982/2013a) örneği olan Türk kahvesi içme deneyiminden farklıdır; gerçekliğin yok olduğunu her şeyin simülasyon olduğunu belirten Baudrillard'ın (1982/2013a) karamsar görüşünün aksine bu özel günlerde, zamanlarda ve mekânlarda içilen Türk kahvesi ve etrafinda oluşan toplumsal ilişkiler ve birliktelikler bir simülasyon, taklit ve sahteliğin örneği değil "hakikat"in kendisidir.

\footnotetext{
5 "Belirli kültürlerdeki belirli besin ve besin birliktelikleri festivaller, bayramlar, kutlamalar, dini adetlerle, kutsal ritüellerle ve bunun yanında hayat döngüsü içindeki bazı önemli anlarla ilişkilendirilebilir" (Beardsworth ve Keil, 2011, s. 91).
} 


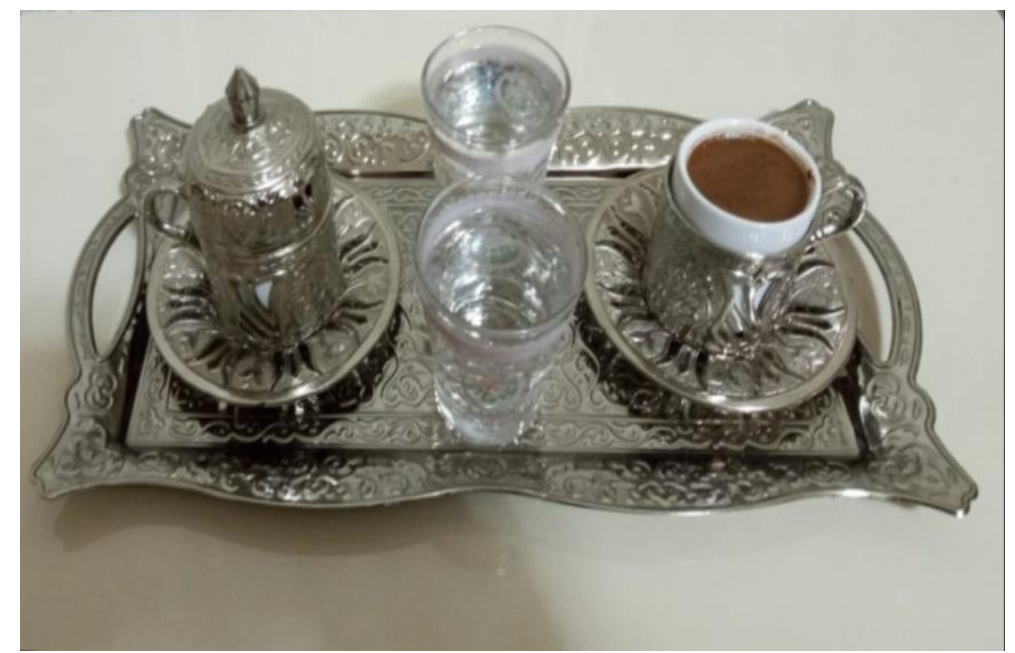

Fotoğraf: Türk Kahvesi

Kaynak: Saadet Karhan tarafindan 19.04.2021 tarihinde çekilmiştir.

Georg Simmel'e göre (2015) nesnel kültür olmadan öznel kültür diye bir şey olamaz; zira bir öznenin gelişimi veya içerisinde bulunduğu durum sadece karşılaştı̆ı işlenmiş nesneleri kendine kattığ 1 takdirde kültür olur (s. 336). Türk kahvesi atasözlerine, şiirlere, deyimlere, türkülere, bilmecelere ve resimlere girerek ritüelleri ile birlikte manevi bir kültür oluşturduğu gibi kendisine has dibek, öğütücü, soğutucu, el değirmeni, kahve kutusu, cezve, fincan, tepsi cinsinden araç ve gereçleriyle maddi bir kültür de meydana getirmiştir. Sosyal, ekonomik, kültürel, sanatsal ve teknolojik değişmeler ve gelişmelerin etkisiyle geçmişten günümüze kadar farklılaşarak gelen bu araç ve gereçler yalnızca satın alınan bir meta değildir; aynı zamanda sembolik anlamlara da sahiptir. Türk kahvesi ikram geleneğinde belli bir usul, kâide, âdet ve âdâb olduğundan kullanılan araç ve gereçlerde önem arz etmektedir. Bu araç ve gereçler, kahve kültürünün, soyut kültürel unsurlarının hayata geçirilmesi ile ortaya çıkmış olan kültürün somutlaşmış halidir. Bursa'ya göre (2015):

Ham kahve çekirdeklerinin kömür ateşi üzerinde demir tavalarda kavrulması, ahşap ya da topraktan yapılmış soğudanlarda öğütülmeye uygun bir dereceye kadar soğutulması, ahşap dibeklerde dövülmesi ya da değirmenlerde çekilmesi ve köz üzerinde cezvede pişirilmesi gibi incelikli usuller kahvenin lezzetini belirlediği gibi, bütün bu süreç içerisinde bir âdâbın oluşmasını sağlamıştır. $\mathrm{Bu}$ anlamda Türk kahvesinin maddi kültürü, hukukun temel anlayışlarından biri olan "usul esasa mukaddemdir" (usul esastan önce gelir) ilkesinin ifade bulduğu bir alandır. Kahve eşyası ve âdâbını birbiriyle ilişkilendirmek, Türk kahvesinin maddi kültürünü görünür kılmayı kolaylaştıracaktır (s. 240).

Türk kahvesinin tüketim kültüründe hiyerarşik bir biçimde yaşa bağlı olarak bir toplumsal farklılaşma ve statü ayrımı da yapılır. Türk kahvesi büyüklere göre çocukların içmemesi gereken bir içecektir. Çocuklar aileden başlayarak diğer sosyal gruplar içerisinde sosyalleşme süreçlerinde neyi, nerede, nasıl, neden, 
kiminle yiyeceklerini/içeceklerini veya yemeyeceklerini/içmeyeceklerini öğrenirler. Çocukların yiyecek ve içeceklere yönelik olan bu normları öğrenme süreçlerinde büyükler çocuklara kimi zaman ödül kimi zaman ceza verirler. Widdowson'a göre (1981) ebeveynler çocukların yeme alışkanlıklarını denetlemek ve çocuklara ne tür şeylerin yemeye uygun olduğunu öğretmek adına bir dizi strateji veya sözel araç kullanabilirler (aktaran Beardsworth ve Keil, 2011, s. 96). Türk kahvesi de büyüklere göre çocukların içmemesi gereken bir içecek olduğundan büyükler uygun olmayan bir ifade biçimi ve ceza yöntemiyle eskiden beri kahve içmek isteyen çocukları korkutmak için Erkan Demir'e göre (2014) "[k]ahve içen çocuklar Arap olur!" (s. 122) demişlerdir. Demir'e göre (2014) çocukların büyükler tarafindan Türk kahvesi içmesinin hoş görülmemesinin nedenleri şunlardır: Türk kahvesinin diğer kültürlerde bulunmayan bir seremonisinin olması ve bir hayli zahmetli bir hazırlanma sürecinden sonra servis edilmesi; büyüklerin yanında çocukların kahve içmesinin Türk örf ve âdetlerine uygun olmaması; çocukları kahvenin zararlarından korumaktır (s. 121, 122). Bir çocuğun "besinsel sosyalizasyonu" (Beardsworth ve Keil, 2011, s. 96) ailede başlar; böylece "habitus"6 (Bourdieu, 1979/2015) çocukluktan itibaren oluşmaya ve şekillenmeye başlar.

Türk kahvesinin önemli bir ritüeli ise sosyolojik, kültürel ve psikolojik bir olgu olan kahve falı pratiğidir. Kahve falı kültürünün kodları çözümlendiğinde toplumda var olan toplumsal ilişkiler, düşünceler ve davranışlar hakkında birçok şey öğrenilebilir. Kahve falında Türk kahvesi içildikten sonra fincanın üstüne tabak kapatılıp dilek tutulur ve "neyse halim çıksın falım" denilerek fincan ile tabak ters çevrilir ve soğuduktan sonra açllarak tabakta ve fincanda telvelerin oluşturduğu şekiller fala bakan kişi ya da falcı tarafindan yorumlanarak gelecekten haber verilir. İslam dininde fal bakmak günah olduğundan batıl bir inanç pratiği ${ }^{7}$ olarak görülmektedir; dolayısıyla fal bakan ve baktıran kişi bu durumu meşrulaştırmak için "fala inanma, falsı da kalma" diye söyleyerek fala bakar ve baktırır. Nuray Alagözlü'ye göre (2007) Türk toplumunda kadınlar arasında kahve içmek ve kahve falına bakmak toplumsal bir olaydır. Ayrıca, kahve falı sosyal ilişkileri meydana getirme, düzenleme ve devam ettirme hususunda önemli bir işleve sahiptir (s. 2, 13). Aslı Büyükokutan'a göre (2012) kahve falı bakma ve baktırma geleneğinin bireysel ve toplumsal işlevleri şunlardır: Bireyin geleceğe dair merakını tatmin etme; psikolojik açıdan rahatlama ve telkin; sosyalleşme, eğlenme, eğlendirme ve

\footnotetext{
6 “Habitus kavramsallaştırması Bourdieu'nün kuramında önemli bir yer tutar ve zaman içinde değişim gösterir. Karmaşık bir kavram olan habitus kısaca bireyleri şekillendiren içselleştirilmiş yapılar olarak tanımlanabilir" (Akarçay, 2016, s. 91).

${ }^{7}$ Ayşe Duvarcı'ya göre (1993, s. 9) İslam dini cahiliye zamanının hurafe ve batıl inançlarına karşı çıkmış; fal olgusunun olumsuz çağrışımlarını yasaklarken bir kelimeyi bir davranışı hayra yormaya izin vermiştir (aktaran Halıc1, 2018, s. 152). İslam dininin kutsal kitab1 Kur'an-1 Kerim'de Ömer Nasuhi Bilmen'e göre (1962) "Maide suresi 90. ayet 'ey müminler, şarap içmek, kumar oynamak, ibadet için dikilen putlar, fal okları, hep şeytanın işinden pis birer şeydir. Onun için bunlardan sakının ki kurtulasınız" (aktaran Duvarcı, 2001, s. 119) buyurmaktadır. İslam dininin fala bakış açısı konusunda daha ayrıntılı bilgi edinmek için (bkz. Duvarcı, 2001, s. 119, 120, 121; Halıc1, 2018, s. $151,152)$.
} 


\section{Toplumsal ve Kültürel Bir İçecek: “Türk Kahvesi”}

hoşça vakit geçirme; kültür ve değer aktarımı; toplumsal ve kültürel uzlaşımların devamını sağlamak (s. 106-107). Türkiye'de kahve falına bakma ve baktırma geleneği çok yaygındır. Ülkemizde fal bakan çok sayıda kafe vardır; ayrıca teknolojik ilerlemelerle beraber kahve falı bakma ve baktırma geleneği internet ortamına taşınarak küresel ve popüler kültürün bir unsuru haline gelmiştir. İzgi Güngör'e göre (2005) fal geleneği folklorik unsurlar taşır; bundan dolayı halkın içinden gelir ve taşıdığı bütün geleneksel ve otantik özellikleriyle halk kültürünün bir parçasıdır. Fakat fal pratiğinin, bugün geleneksel anlamını giderek kaybettiği; elektronik ortamlardaki yeni görünümleriyle sistematik, profesyonelce ve ticari anlamda bakılan ve çok kolay, anlık ve gündelik olarak erişilen ve tüketilen kitlesel, sıradan ve moda halinde tüketilen bir popüler kültürel pratiğe dönüştüğü gözlemlenmektedir (s.172). Kahve falına bakma ve baktırma geleneği bugün "tüketim toplumu"nda (Baudrillard, 1970/ 2013b) geleneksel boyutundan siyrilıp materyalist bir boyuta geçerek standartlaşmış, rasyonelleştirilmiş, ticarileşmiş, kitleselleşmiş, metalaşmış; böylece "kültür endüstrisi”nin (Adorno, 2011) bir parçası haline gelmiştir. Günümüzde kahve falı pratiği; fal bakmayı meslek haline getirmiş "yeni kültür aracıları" (Bourdieu, 1979/2015) falcılar tarafindan bireyleri maddi ve manevi açıdan sömüren bir araç olmuştur. Ayrıca, geleneksel olarak en fazla kadınlar arasında gerçekleştirilen kahve falı bakma ve baktırma geleneği bugün toplumsal cinsiyet açısından da değişime ve dönüşüme uğramıştır. Artık fal bakma ve baktırma geleneği erkekler arasında da çok yaygınlaşmıştır.

Günümüzde küreselleşme sürecinin iktisadi, teknolojik, kültürel ve sosyal boyutlarının toplumsal ve gündelik yaşama tesir etmesi ile birlikte insanların kahve tüketim alışkanlıkları değişmiştir. Ayrıca bugün dünyanın herhangi bir ülkesinde bir süpermarkette tam bir "zaman-mekân sıkışması" (Harvey, 1990/2012) şeklinde birçok ürünün arasında Türk kahvesini görebildiğimiz gibi bir "tüketim katedrali" (Ritzer, 2016a) olan büyük bir alışverişmerkezin de yer alan "McDonaldlaşmış" (Ritzer, 2016b) ve "gösterişçi tüketim"in (Veblen, 1899/2015) sergilendiği Starbucks gibi kent hayatının orta sınıf kesimlerine hitap eden ve kâr elde etmek amacıyla kendisini ulusal ve kültürel şartlara uyarlamış küresel kahve zincirlerinde bir simülasyon örneği olarak yerel kültürden ihraç edilmiş olan Türk kahvesini içebiliriz. Gerçi mutfaklarımızda tam bir "zaman-mekân sıkışması" halinde zorunlu olan birtakım toplumsal ve ekonomik koşullardan dolayı Türk kahve makinesi, elektrikli cezve, hazır kahve çeşitleri gibi küresel ve modern endüstriyel ürünlere kapılarını açarak küreselle yerelin bir arada bulunduğu bir mekâna dönüşmüştür. Burada belirtilmesi gereken husus şudur ki Batının kapitalist kültürü yerel kültürler üzerinde bir tahakküm oluşturmaktadır; ancak yerel kültürlerde küresel olan karşısında topyekûn teslimiyetçi ve edilgen değildir; dolayısıyla küresel olana direnme, uyarlama, melezleşme, biçimlendirme, kendine katma, kültürel korumacılık vb. tepkileri verirler. ${ }^{8} \mathrm{Bu}$ bağlamda yerel olan bu mutfaklar aynı zamanda diyalektik, dinamik, yaratıc1, heterojen, çok boyutlu ve etkileşimli

\footnotetext{
${ }^{8}$ Küresel ile yerel olan arasındaki "diyalektik" ilişki konusunda daha ayrıntılı bilgi için (bkz. Berger ve Huntington 2002/2003; Ichijo ve Ranta, 2016/2018; Tomlinson, 1999/2013).
} 
ilişkilerin olduğu kültürel bir alandır; çünkü yerel kültüre ait olan pratikler, ritüeller ve semboller -ithal edilen ya da yerel tarafindan küreselin ilkeleri kopyalanarak piyasaya sürülen- ticari metalara hemen kendi damgasını vurur. Örneğin bazen zorunlu ve pratik sebeplerden dolayı içilen hazır paket bir Türk kahvesini kâğıt bardağa değil de bir fincana koyarak içip hemen ardından kahve falına bakmak hazır paket Türk kahvesine kültür alıcısının kattı̆̆ 1 kültürel anlam ve katkıdır. Köklü bir geçmişe sahip olan Türk kahvesi kültürü bir "icat edilmiş gelenek" (Hobsbawn, 1983/2006, s. 2) olmadığından süreksiz bir şey değildir ve sürekliliği vardır; dolayısıyla Türk kahvesi gibi belli bir zamana, coğrafyaya, tarihe bağlı bir sürekliliği olan ve yakın bir geçmiş zamanda "icat edilmiş" olmayan 500 yıllık bir gelenek ve kültüre sahip olan bir kültürel miras kolay kolay ortadan kalkmaz.

\section{Sonuç}

Kahve, Osmanlı'ya ilk girdiği günden itibaren her ne kadar yasaklamalarla karşılaşmışsa da bunlara direnmiş "muhalif" bir içecek olarak toplumun gündelik, sosyal ve kültürel yaşamında adeta kendisine mahsus köklü bir gelenek ve medeniyet oluşturmuştur; ayrıca Türkler menşei Etiyopya ve başlangıçta bir "sûfî içeceği” olan kahveyi Avrupa'ya da tanıtmış ve yaymışlardır.

$\mathrm{Bu}$ çalışmada atasözlerine, şiirlere, deyimlere, türkülere, bilmecelere ve resimlere girerek gelenekleri ve ritüelleri ile birlikte manevi ve dibek, öğütücü, soğutucu, el değirmeni, kahve kutusu, cezve, fincan, tepsi türünden araç ve gereçleriyle maddi bir kültür meydana getirmiş ve 500 yıllık sosyal, kültürel, siyasi ve tarihsel bir geçmişe sahip kültürel bir miras olan Türk kahvesi kültürü ve geleneği tarihi kaynaklardan da faydalanarak multidisipliner ve sosyolojik açıdan ele alınmış ve önemi ortaya konulmaya çalışılmıştır.

Türk kahvesi sosyolojik, sanatsal, siyasal, tarihi, kültürel ve ekonomik bir değere sahiptir; bu nedenle Türkiye bu kültürel mirası korumak için girişimlerde bulunmuştur. Neticesinde ise köklü bir geleneğe ve kültüre sahip olan Türk kahvesi 2013 tarihinde UNESCO tarafindan meydana getirilen "İnsanlığın Somut Olmayan Kültürel Mirasının Temsili Listesi”ne girmiş; böylece yerel kültürel kimliğin bir unsuru olan bu kültürel miras evrenselleşmiş ve korunma altına alınmıştır.

KAYNAKÇA

AÇIKGÖZ, N. (1999). Kahvenâme (klâsik Türk edebiyatında kahve). Akçă̆ Yayınlar1.

ADORNO, T. W. (2011). Kültür endüstrisi/Kültür yönetimi (6. bs.). (N. Ülner, M. Tüzel ve E. Gen, Çev.). E. Gen (Yay. haz.). İletişim Yayınları.

AHISKA, M. ve YENAL, Z. (2006). Aradığınız kişiye şu an ulaşılamıyor/Türkiye'de hayat tarzı temsilleri 1980-2005. Osmanlı Bankası Arşiv ve Araştırma Merkezi.

AKARÇAY, E. (2016). Beslencenin sosyolojisi/Orta sinuf(lar)ın yeme içme ve eğlence örüntüleri. Phoenix Yayınevi. 
ALAGÖZLÜ, N. (2007). Bir söylem türü olarak kahve falına yönelik bir inceleme: Kahve falı ve ideoloji. Edebiyat Fakültesi Dergisi, 24(1), 1-22. Erişim adresi: https://dergipark.org.tr/tr/download/article-file/597801

ARENDONK, C. V. (1967). Kahve. (A. Adıvar, R. Arat, A. Ateş, C. Baysun ve B. Darkot tarafindan leyden tab'1 esas tutularak telif, tâdil, ikmâl ve tercüme sureti ile neşredilmiştir), İslâm ansiklopedisi/İslâm âlemi tarih, coğrafya, etnografya ve biyografya lugatı (Cilt 6), (2. bs.) içinde (ss. 95-100). Milli Eğitim Basımevi.

AYVAZOĞLU, B. (2019). Kahveniz nasll olsun? Türk kahvesinin kültür tarihi (4. bs.). Kap1 Yayınları.

BAUDRILLARD, J. (2013a). Simülakrlar ve Simülasyon (7. bs.). (O. Adanır, Çev.). T. Takış (Yay. haz.). Doğu Batı Yayınları. (Orijinal çalışma 1982 yılında yayımlanmıştır).

BAUDRILLARD, J. (2013b). Tüketim toplumu söylenceleri yapıları (6. bs.). (H. Deliceçaylı ve F. Keskin, Çev.). Ayrıntı Yayınları. (Orijinal çalışma 1970 yılında yayımlanmıştır).

BEARDSWORTH, A. ve KEIL, T. (2011). Yemek Sosyolojisi/Yemek ve toplum çalışmasına bir davet. (A. Dede, Çev.). S. Torlak (Ed.). Phoenix Yayınevi.

BERGER, P. L ve HUNTINGTON, S. P. (Ed.). (2003). Bir küre bin bir küreselleşme/Çağdaş dünyada kültürel çeşitlilik. (A. Ortaç, Çev.). Kitap Yayınevi. (Orijinal çalışma 2002 yılında yayımlanmıştır).

BİNGÜL, İ. (2013). Osmanlı'da kahvehane ve toplumsal hayat mekanlarl. Gram Yayınlar1.

BİRSEL, S. (1983). Kahveler kitabı (2. bs.). Türkiye İş Bankası Kültür Yayınları.

BOURDIEU, P. (2015). Ayrım/Beğeni yargısının toplumsal eleştirisi. (D. FuratŞannan ve A. Günce-Berkkurt, Çev.). G. Çeğin (Yay. haz.). Heretik Yayınları. (Orijinal çalışma 1979 yılında yayımlanmıştır).

BURSA, N. (2015). Bir keyfin âdâbı: Çekirdekten fincana Türk kahvesinin maddi kültürü. E. Pekin (Ed.), Bir taşım keyif/Türk kahvesinin 500 yıllık öyküsü içinde (ss. 239-281). T.C. Kültür ve Turizm Bakanlığı Topkapı Sarayı Müzesi; Türk Kahvesi Kültürü ve Araştırmaları Derneği Yayını.

BÜYÜKOKUTAN, A. (2012). Muğla'daki kahve falına bakma geleneği üzerine bir değerlendirme. Folklor/Edebiyat Dergisi, 18(71), 97-112. Erişim adresi: https://dergipark.org.tr/tr/download/article-file/255394

ÇELEBİ, K. (2018). Mîzânü 'l-Hakk Fî İhtiyâri'l-Ehakk/Ihtilaf içinde itidal (2. bs.). S. Uludağ (Haz.). Dergâh Yayınları.

DEMİR, E. (2014). Çocukluğumuzdan yadigâr bir tembih: "Kahve içme Arap olursun!”. E. Gürsoy-Naskali (Ed.), Türk kahvesi kitabı (3. bs.) içinde (ss. 117-123). Kitabevi Yayınları.

DUVARCI, A. (2001). Halk kültürü uygulamalarından biri olan fal geleneğinin değerlendirilmesi. Türk Halk Kültürü Özel Sayısı, 13(37), 117-130. Erişim adresi: https://erdem.gov.tr/tam-metin-pdf/411/tur

EVREN, B. (1996). Eski İstanbul'da kahvehaneler. Milliyet Yayınları. 
FISCHLER, C. (1988). Food, self and identity. Social Science Information, 27(2), 275-292. doi:10.1177/053901888027002005

FOUCAULT, M. (2005). Özne ve iktidar/Seçme yazılar 2 (2. bs.). (I. Ergüden ve O. Akınhay, Çev.). F. Keskin (Yay. haz.). Ayrıntı Yayınları.

GIDDENS, A. (2012). Sosyoloji. (H. Özel, Çev.). C. Güzel (Yay. haz.). Kırmızı Yayınlar1.

GİRGINOL, C. R. (2018). Kahve/Topraktan fincana (7. bs.). A7 Kitap.

GÜNGÖR, İ. (2005). Popüler kültür ürünü olarak fal. Iletişsim, 21, 169-202. Erişim adresi: http://www.irfanerdogan.com/dergiweb2008/21/6.\%20makale.pdf

GÜRSOY-NASKALİ, E. (Ed.). (2014). Türk kahvesi kitabı (3. bs.). Kitabevi Yayınlar1.

HALICI, G. (2018). Popüler kültürün ekonomik bir olgusu: Fal. Karadeniz Araştırmaları Dergisi, 15(58), 146-159. doi:10.12787/KARAM1249

HARVEY, D. (2012). Postmodernliğin durumu/Kültürel değişimin kökenleri (6. bs.). (S. Savran, Çev.). M. Gürsoy-Sökmen (Yay. haz.). Metis Yayınları. (Orijinal çalışma 1990 yılında yayımlanmıştır).

HATTOX, R. S. (1996). Kahve ve kahvehaneler/Bir toplumsal içeceğin Yakındoğu'daki kökenleri. (N. Elhüseyni, Çev.). A. Anadol (Yay. haz.). Tarih Vakfı Yurt Yayınları. (Orijinal çalışma 1985 yılında yayımlanmıştır). HOBSBAWN, E. (2006). Giriş: gelenekleri icat etmek. E. Hobsbawn ve T. Ranger (Der.). (M. M. Şahin, Çev.). Geleneğin icadl içinde (ss. 1-18). Agora Kitaplığı. (Orijinal çalışma 1983 yılında yayımlanmıştır).

ICHIJO, A. ve RANTA, R. (2018). Yemek ve ulusal kimlik/Gündelik yaşamdan küresel siyasete. (E. Ataseven, Çev.). S. Aktuyun (Yay. haz.). Ayrınt1 Yayınları. (Orijinal çalışma 2016 yılında yayımlanmıştır).

IŞIN, E. (2006). Bir içecekten daha fazla: Kahve ve kahvehanelerin toplumsal tarihi. S. Özpalabıyıklılar (Ed.), Tanede saklı keyif, kahve içinde (ss. 1043). Yap1 Kredi Yayınları.

KAFADAR, C. (2014). How dark is the history of the night, how black the story of coffee, how bitter the tale of love: The changing measure of leisure and pleasure in early modern Istanbul. A. Öztürkmen \& E. Birge Vitz (Ed.) in Mediaval and early modern performance in the Eastern Mediterranean (pp. 243-269). Brepols. Erişim adresi:https://sites.duke.edu/rethinkingglobalcities/files/2014/09/howdark.p df.

KUZUCU, K. ve KOZ, M. S. (2015). Türk kahvesi. M. S. Koz (Ed.).Yapı Kredi Yayınları.

KUZUCU, K. (2015). Türk kahvesinin kısa tarihi. M. S. Koz (Ed.), Türk kahvesi içinde (ss. 15-193). Yapı Kredi Yayınları.

MIKHAIL, A. (2014). Gönül arzu eder ki: Toplumsal cinsiyet, kentsel mekân ve Osmanlı kahvehaneleri. D. Sajdi (Der.). (A. Onacak, Çev.). Osmanlı laleleri, Osmanlı kahvehaneleri/On sekizinci yüzyılda hayat tarzı ve boş vakit eğlenceleri içinde (ss. 175-225). Koç Üniversitesi Yayınları. 
MOON, R. (1998). The coffee book/More than 40 delicious and refreshing recipes for drinks and desserts. Courage Books.

MORRIS, J. (2020). Coffee a global history. Reaktion Books Ltd.

NEUMAN, W. L. (2010). Toplumsal araştırma yöntemleri/Nitel ve nicel yaklaşımlar 2 (4. bs.). (S. Özge, Çev.). Yayınodası Yayıncılık.

PEÇEVİ, İ. E. (1981). Peçevi Tarihi: I. B. S. Baykal (Haz.). Kültür Bakanlığı Yayınlar1.

PEKİN, E. (Ed.). (2015). Bir taşım keyif/Türk kahvesinin 500 yıllık öyküsü. T.C. Kültür ve Turizm Bakanlığı Topkapı Sarayı Müzesi; Türk Kahvesi Kültürü ve Araştırmaları Derneği Yayını.

PETROPOULOS, E. (2019). Yunanistan'da Türk kahvesi. (H. Millas, Çev.). Ç. Çevik (Ed.). Kırmızı Kedi Yayınevi. (Orijinal çalışma 1979 yılında yayımlanmıştır).

RITZER, G. (2016a). Büyüsü bozulmuş dünyayı büyülemek/Tüketim katedrallerindeki süreklilik ve değişim (Genişletilmiş 4. bs.). (F. Payzın, Çev.). Y. E. Ceren (Ed.). Ayrıntı Yayınları.

RITZER, G. (2016b). Toplumun McDonaldlaştırılması/Çă̆daş toplum yaşamının değişen karakteri üzerine bir inceleme (4. bs.). (A. E. Pilgir, Çev.). Ayrıntı Yayınları.

SARAÇGİL, A. (1999). Kahve'nin İstanbul'a girişi (16. ve 17. yüzyıllar). H. Desmet-Grégoire ve F. Georgeon (Ed.). (M. Atik ve E. Özdoğan, Çev.). Doğu'da kahve ve kahvehaneler içinde (ss. 27-41). Yapı Kredi Yayınları.

SAVAŞ-IŞIKHAN, S. (2014). Türk kahvesi geleneği ve kahve fincanları. E. Gürsoy-Naskali (Ed.), Türk kahvesi kitabı (3. bs.) içinde (ss. 407-420). Kitabevi Yayınları.

SCHIVELBUSCH, W. (2000). Keyif verici maddelerin tarihi/Cennet, tat ve mantı. (Z. Aksu-Yılmazer, Çev.). Dost Kitapevi Yayınları. (Orijinal çalışma 1980 yılında yayımlanmıştır).

SENNETT, R. (2013). Kamusal insanın çöküşü (4. bs.). (S. Durak ve A. Yılmaz, Çev.). T. Birkan ve T. Tosun (Yay. haz.). Ayrıntı Yayınları.

SIMMEL, G. (2015). Bireysellik ve kültür (2. bs.). (T. Birkan, Çev.). M. GürsoySökmen (Yay. haz.). Metis Yayınları.

SÖKMEN, C. (2019). Aydınların iletişim ortamı olarak eski Ístanbul kahvehaneleri (4. bs.). Ötüken Neşriyat A.Ş.

STELLA, A. (1997). The book of coffee. Flammarion.

SWARTZ, D. (2011). Kültür ve iktidar/Pierre Bourdieu'nün Sosyolojisi. (E. Gen, Çev.). L. Cantek (Ed.). İletişim Yayınları. (Orijinal çalışma 1997 yılında yayımlanmıştır).

THÉVENOT, J. (2014). Thévenot seyahatnamesi (2. bs.). (A. Berktay, Çev.). S. Yerasimos (Ed.). Kitap Yayınevi.

TOMLINSON, J. (2013). Küreselleşme ve kültür (2. bs.). (A. Eker, Çev.). N. Özok (Yay. haz.). Ayrıntı Yayınları. (Orijinal çalışma 1999 yılında yayımlanmıştır).

TOROS, T. (1998). Kahvenin öyküsü. İletişim Yayınları. 
VEBLEN, T. (2005). Aylak sinifin teorisi/Kurumların iktisadi incelemesi. (E. Kırmızıaltın ve H. Bilir, Çev.). H. A. Öznazik (Yay. haz.). Heretik Yayınları. (Orijinal çalışma 1899 yılında yayımlanmıştır).

YERASIMOS, M. (2019). Evliyâ Çelebi Seyahatnâmesi'nde yemek kültürü/Yorumlar ve sistematik dizin. K. Erdur (Ed.). Yap1 Kredi Yayınları. WILD, A. (2005). Black gold: A dark history of coffee. Harper Perennial. 